\title{
PLAGIO Y ÉTICA DE LA INVESTIGACIÓN CIENTÍFICA
}

\section{PLAGIARISM AND ETHICS OF SCIENTIFIC RESEARCH}

\section{ALEJANDRo Miranda MonTeCinos ${ }^{*}$}

A comienzos del año 2011, la comunidad internacional se sorprendió al conocer el caso del ministro de defensa alemán, Karl Theodor zu Guttenberg -a la sazón el político alemán más valorado, con un apoyo del 70\%-, quien perdió su título de doctor en Derecho y tuvo que renunciar a su cargo público tras descubrirse que había plagiado aproximadamente el $20 \%$ de las 475 páginas de su tesis doctoral (es decir, unas 95 páginas).

Más recientemente se ha hecho público el caso del presidente de Hungría, Pál Schmitt, a quien la Semmelweis University de Budapest le revocó el título de Doctor luego de comprobarse que había plagiado más de 197 páginas de las 215 que componen su tesis doctoral sobre los Juegos Olímpicos modernos. Este escándalo terminó con la dimisión de Schmitt a la presidencia de Hungría, el 2 de abril de 2012.

Estos casos constituyen una muestra de la vigencia que tiene el problema del plagio. A pesar de que se trata de una práctica que ha existido a lo largo de toda la historia, hoy en día concurren ciertas condiciones que hacen del plagio un problema especialmente apremiante. Parece claro que

\footnotetext{
* Licenciado en Derecho, Pontificia Universidad Católica de Chile. Abogado. Magíster en Investigación Jurídica, Universidad de los Andes. Doctor en Derecho, Universidad de los Andes. Profesor de Filosofía del Derecho en la Universidad de los Andes. El autor agradece los comentarios y sugerencias de los profesores Joaquín García-Huidobro, Carlos Martínez Cinca y José Antonio Poblete.
}

la principal de estas condiciones tiene que ver con el acceso a Internet y la consiguiente posibilidad de obtener grandes cantidades de información en formatos fácilmente reproducibles. Esto ha dado lugar al surgimiento de una cultura del copy-paste -la denominación informática del plagio-, que se empieza a desarrollar, casi sin conciencia, en la etapa escolar, y luego se extiende, ya en forma de hábito, a la vida universitaria.

Pero también hay razones adicionales que explican el aumento del plagio en el nivel de los investigadores profesionales: el incremento en las exigencias del trabajo científico pone sobre ellos la necesidad de publicar la mayor cantidad de trabajos en el menor tiempo posible (lo que los anglosajones han denominado síndrome publish or perish), por lo que muchos se ven tentados simplemente a reproducir pensamientos ajenos, sin respetar adecuadamente la autoría sobre las ideas. Un ejemplo conocido es el caso del Dr. Slutsky de la Universidad de California San Diego, que publicó 137 artículos en 7 años, es decir, publicó a una razón de 1 artículo por cada 13 días laborales. Llevados los antecedentes a una comisión investigadora -por la tasa sorprendente de productividad académica del Dr. Slutsky-, se comprobó que el 56\% de los trabajos eran de dudosa validez y el $9 \%$ eran derechamente fraudulentos ${ }^{1}$.

\footnotetext{
1 Véase Aluja, Martín, \& Birke, Andrea (2004): "Panorama general sobre los principios éticos aplicables a la investigación científica y la educación supe-
} 
Esta expansión del fenómeno del plagio ha sido constatada también por las encuestas: en una encuesta realizada en México a un grupo de académicos y científicos se determinó que el plagio está entre los tres problemas éticos que se perciben como más frecuentes o habituales en la comunidad científica (los otros dos son la falta de rigor científico y el fraude) ${ }^{2}$.

Frente a este escenario surge la necesidad de volver a teorizar sobre la materia para tener claridad acerca de los principios que la rigen. Puesto que mi campo propio de estudio es el de la Ética y la Filosofía del Derecho, abordaré aquí el problema del plagio en su relación con lo que se podría denominar "ética de la investigación científica". Con esta finalidad, procederé del siguiente modo. Voy a dividir la exposición en ocho partes. En la primera, explicaré a qué me refiero con "ética de la investigación científica”; en la segunda, estudiaré la etimología y sentido de la noción de "plagio"; en la tercera, y para precisar más la esencia del plagio, ahora por vía negativa, examinaré aquello que no es necesario para que se constituya un plagio; en la cuarta, presentaré los argumentos para demostrar la ilicitud moral del plagio; en la quinta, trataré del principio de presunción de autoría y del derecho de cita; en la sexta, analizaré algunas formas especiales de plagio; en la séptima, reflexionaré sobre las medidas que se pueden adoptar para

rior", en: Aluja, M., \& Birke, A. (coords.), El papel de la ética en la investigación cientifica y la educación superior ( $2^{\mathrm{a}}$ ed., México, Fondo de Cultura Económica) pp. 87-143.

2 Domínguez, César, \& Macías-Ordóñez, Rogelio (2004): “El que no transa no avanza': la ciencia mexicana en el espejo", en Aluja \& Birke (coords.), El papel de la ética en la investigación cientifica y la educación superior (2a ed., México, Fondo de Cultura Económica) pp. 230-231. combatir el plagio, y, finalmente, terminaré enunciando algunos breves consejos para una "buena conducta científica".

\section{LA ÉTICA DE LA INVESTIGACIÓN CIENTÍFICA}

Desde la segunda mitad del siglo XX, y en especial a partir de la década de los 80 , se viene hablando en forma creciente de una "ética de la investigación científica". Se emplea esta denominación para referirse al conjunto de principios morales específicos que regulan la actividad de la investigación científica. La ética de la investigación científica, entonces, es una rama de la ética especial, que versa sobre el modo como los principios comunes de la moralidad de los actos humanos se especifican en un ámbito determinado de la vida del hombre, en este caso, el de la investigación científica y el trabajo académico. La noción de "ética de la investigación científica” ha avanzado de la mano de la noción de "mala conducta científica" o "mala conducta en la investigación". Es decir, se ha entendido que la función de la ética de la investigación científica es definir y delimitar con exactitud cuándo nos encontramos en presencia de una mala conducta científica. Como ocurre en general con las cuestiones morales, esta no es una tarea sencilla, y por eso los cultores de esta disciplina sostienen que un paso inicial ha de ser la creación de códigos de ética de la investigación científica y la conformación de comités de ética de la investigación científica integrados por expertos.

En Estados Unidos, la Oficina de Integridad en la Investigación (Office of Research Integrity), ORI, ha propuesto una definición de "mala conducta científica" o "mala conducta en la investigación" (research misconduct) que se ha hecho muy 
conocida porque ha servido de base para las definiciones que proponen otros organismos. Según la ORI, la mala conducta en la investigación científica consiste en la "fabricación, falsificación o plagio al proponer, realizar o revisar investigación, o al reportar resultados de una investigación"3. Y luego añade: “(a) La fabricación es el maquillaje de datos o resultados y el registro o reporte de ellos. (b) La falsificación es la manipulación de materiales, equipamientos o procesos de investigación, o la alteración u omisión de datos o resultados, de tal modo que la investigación no esté exactamente representada en el registro de investigación. (c) El plagio es la apropiación de las ideas, procesos, resultados o palabras de otra persona sin dar el correspondiente crédito" 4 . Para terminar con su definición, la ORI precisa que "(d) [l]a mala conducta en la investigación no incluye el error honesto o las diferencias de opinión" 5 .

Aunque la definición de la ORI es ciertamente incompleta -pues existen otras formas de mala conducta científica que no señala: como las interpretaciones torcidas de las ideas ajenas, la caricaturización del oponente en una discusión académica, las citas parciales y descontextualizadas- ella recoge en un texto breve tres de las malas prácticas que presentan una mayor gravedad. Junto con el plagio, la ORI menciona la fabricación de datos y la falsificación de datos. Tanto en la fabricación de datos como en la falsificación de datos se presentan datos falsos como si fueran verdaderos,

\footnotetext{
3 Office of Research Integrity of the U.S. Department of Health and Human Services (s. f.): "Definition of Research Misconduct". Disponible en: http://ori.hhs.gov/misconduct/definition_misconduct. shtml [fecha de consulta: 7 de septiembre de 2012].

4 Office of Research Integrity (s. f.).

5 Office of Research Integrity (s. f.).
}

pero ellas difieren en que, en la fabricación de datos, el sujeto no cuenta con los datos verdaderos, mientras que en la falsificación se cuenta con datos verdaderos pero se los altera para que se ajusten a los resultados de la investigación o a las hipótesis de trabajo que se han propuesto al inicio de un proyecto. Uno de los ejemplos más conocidos de fabricación de datos es el del falso descubrimiento del cráneo del hombre de Piltdown, que hizo creer a toda la comunidad científica que se había encontrado el eslabón perdido ${ }^{6}$.

\section{ETIMOLOGÍA Y SIGNIFICADO DE LA VOZ "PLAGIO"}

"Plagio" es el sustantivo masculino que designa la acción y efecto de plagiar. Proviene del latín plagium, que significa 'secuestro'. Según el Oxford Latin Dictionary, plagium procede, a su vez, de plaga, que designa una red empleada para cazar ${ }^{7}$. Corominas señala que plagium procede del griego $\pi \lambda \alpha ́ \gamma$ ios (plágios), que significa 'trapacero' o 'trapacista', es decir, el que con astucias, falsedades y mentiras procura engañar a alguien en un asunto ${ }^{8}$. Teodoro Mommsen coincide con Corominas en la etimología, pero vincula el griego plágios con otra de sus acepciones, la de 'oblicuo' o 'torcido', que, según Mommsen, también se podía entender en sentido moral ${ }^{9}$.

\footnotetext{
6 Véase Aluja y Birke (2004) p. 100.

7 Véase Oxford Latin Dictionary (1968) s. v. 'plagium'.

8 Véase Corominas, Joan (1973): Breve diccionario etimológico de la lengua castellana ( $3^{\mathrm{a}}$ ed., Madrid, Gredos).s. v. 'plagio'. Corominas también reconoce, con todo, que la palabra plagium tiene la misma raíz griega que plaga: véase Corominas, Joan, \& PasCuAL, José (1991-1997): Diccionario crítico etimológico castellano e hispánico (Madrid, Gredos). s. v. 'llaga'.

9 Véase Mommsen, Teodoro (1999): Derecho Penal
} 
En la Roma antigua, "plagiar" consistía, o en comprar a un hombre libre sabiendo que lo era y retenerlo en servidumbre, o en utilizar un esclavo ajeno como si fuera propio $^{10}$. Este segundo sentido parece estar en el origen del uso de la voz plagio con el significado que ahora nos convoca. En efecto, por analogía con el que utiliza un esclavo ajeno como si fuera propio, se comienza a llamar "plagiario" al que utiliza una obra ajena como si fuera propia. Esta extensión del lenguaje se le atribuye al poeta latino Marco Valerio Marcial, quien escribió a finales del siglo I d. C. Marcial dedica un buen número de sus epigramas a atacar a Fidentino, que había copiado sus escritos. Cuando describe la acción del plagiario Fidentino, Marcial recurre a la metáfora de la esclavitud:

“Te confío, Quinciano, nuestros... -si es que puedo llamar nuestros a los libros que recita un poeta amigo tuyo-: si se quejan de pesada esclavitud, acude a su defensa y respáldales suficientemente, $y$, cuando aquel se declare dueño, di que son míos y que se les ha concedido la libertad"11.

O sea, el plagiario es, en este nuevo sentido, una especie de "secuestrador" de libros o del trabajo intelectual ajeno.

Si se revisan las definiciones que los diccionarios más importantes ofrecen de este sentido del verbo "plagiar"12, se puede

romano (trad. P. Dorado, Santa Fe de Bogotá, Temis) p. 482.

10 Véase Digesto 48, 15: de lege Fabia de plagiariis.

11 Marcial, Marco Valerio (2001): Epigramas (trad.

A. Ramírez, Gredos, Madrid) I, p. 52.

12 Véanse, por ejemplo, Real Academia Española (2001): Diccionario de la lengua española (22a ed., Madrid, Espasa); Moliner, María (2007): Dicciona- constatar que todos convienen en que el plagio contempla los siguientes elementos. En primer lugar, consiste en una copia de una obra ajena. En segundo lugar, esa copia incluye una intención fraudulenta, que se traduce en presentar lo ajeno como si fuera propio. Este segundo elemento, i. e., presentar lo ajeno como si fuera propio, es lo característico del plagio. Ya lo ve así el propio Marcial, en otro de los epigramas que dedica al plagiario Fidentino:

"La fama dice que tú, Fidentino, recitas mis escritos a la gente como si fueran tuyos. Si quieres que se digan míos, te enviaré gratis los versos: si quieres que se digan tuyos, cómpralos para que no sean míos"13.

Por último, como tercer elemento, algunas definiciones exigen que la copia de la obra ajena sea substancial. Este elemento está contenido, por ejemplo, en el Diccionario de la Lengua Española de la Real Academia Española, que define "plagiar" como "copiar en lo sustancial obras ajenas, dándolas como propias". La exigencia de que la copia sea substancial tiene relevancia para la denominada "excepción de insignificancia", a la que me referiré luego.

En cuanto a su materia, el plagio puede recaer (i) sobre ideas, pensamientos o juicios ajenos (en casos extremos puede plagiarse una obra completa, que contiene un conjunto de ideas, pensamientos o juicios); o puede recaer (ii) sobre datos obtenidos como resultado de las investigaciones de un terce-

rio de uso del español (3a ed., Madrid, Gredos); SeCo, Manuel; Andrés, Olimpia; \& Ramos, Gabino (1999): Diccionario del español actual (Madrid, Aguilar); CASAREs, Julio (2004): Diccionario ideológico de la lengua española (2a ed., Barcelona, Gustavo Gili) 887 pp.

13 Marcial(2001) I, p. 29. 
ro. En lo sucesivo utilizaré la palabra "obra" para referirme, en general, a cualquiera de los elementos susceptibles de ser plagiados.

Naturalmente, no se comete plagio en toda ocasión en que se invoca una idea o juicio ajeno sin citar la fuente. No hay plagio, por ejemplo, (i) cuando se utilizan verdades públicamente reconocidas $(v . g r$., no es necesario citar a nadie para afirmar la redondez de la tierra); (ii) cuando se utilizan ideas generalmente compartidas por todos los que cultivan una cierta rama del saber; (iii) cuando se escribe en el contexto de una determinada escuela de pensamiento que asume ciertas tesis generales; ni (iv) cuando se puede invocar la "excepción de insignificancia", es decir, cuando por inadvertencia, error u olvido se omite consignar una cita correspondiente a una idea que, en el contexto, no es demasiado significativa, en especial si se ha citado en otras oportunidades la obra ajena en la cual esa idea está contenida ${ }^{14}$.

Aunque el plagio se suele definir haciendo referencia a la intención fraudulenta, para que se cometa plagio no es estrictamente necesario que el plagiario obre intencionalmente. El plagio puede cometerse intencionalmente o por negligencia, i. e., con dolo o con culpa. Al igual que todas las especies de actos humanos moralmente relevantes, el plagio se configura, en su caso central o analogado principal, cuando existe intención plagiaria, esto es, cuando intencionalmente se presenta una obra ajena como si fuera propia. Sin embargo, las especies de los actos humanos también admiten formas secundarias o análogas, y de este modo se puede configurar el plagio también por negligencia. Así, cuando por desidia un

14 Véase Toller, Fernando (2011): "Propiedad intelectual y plagio en trabajos académicos y profesionales", Revista la Propiedad Inmaterial, 15, pp. 85-97. investigador no conoce las exigencias morales del trabajo académico, o no domina, por ejemplo, las técnicas de citación, y esto lo lleva a omitir los créditos ajenos en un trabajo que está realizando, comete igualmente una forma de plagio, aunque no haya tenido la intención de presentar como originales y propias las ideas de otro. Naturalmente, esta es una forma menos grave de plagio, y así deberá ser considerada al momento de la aplicación de sanciones.

\section{QUÉ NO ES NECESARIO PARA QUE SE CONSTITUYA UN PLAGIO}

En el acápite precedente se han mencionado los elementos esenciales del plagio, es decir, aquellas circunstancias que deben concurrir para que estemos en presencia de una conducta que pueda calificarse como plagio. Es importante también, para alcanzar una mayor claridad conceptual, referirse a algunas condiciones que, aunque podría parecerlo, no son necesarias para que se configure un plagio.

En primer lugar, no es necesario, para que se cometa plagio, que la obra plagiada esté publicada. El plagio puede recaer sobre obras publicadas o sobre obras inéditas. Comete plagio, por tanto, el alumno que copia y presenta como propio, por ejemplo, un apunte de clase confeccionado por un profesor para que circule entre sus alumnos.

En segundo lugar, para que se cometa plagio no es necesario, tampoco, que la obra del plagiario esté publicada. La publicación de un plagio solo es señal de una mayor desvergüienza en el autor del plagio, pero desde luego no es requisito para que se configure la falta.

En tercer lugar, para que se cometa plagio no es necesario que la conducta en cuestión esté castigada en el orden de la ley 
civil o penal. Puesto que no es función de la ley reprimir o castigar todos los actos malos, puede suceder, y de hecho sucede, que muchas formas de plagio no estén castigadas por la ley positiva. Eso no quiere decir, evidentemente, que las formas de plagio que no son sancionadas ni en el orden civil ni el orden penal sean lícitas. Toda forma de plagio es ilícita, y las que no son castigadas por el ordenamiento jurídico general deberían siempre recibir una sanción disciplinar o administrativa en el orden académico.

En cuarto lugar, no es necesario, para que se cometa plagio, que el plagiario transcriba textualmente la obra ajena. También se puede cometer plagio resumiendo o parafraseando las ideas de otro. Solo en los casos más burdos el plagiario transcribe ad litteram una parte o la totalidad del texto original. Pero en los plagios más sofisticados el plagiario se apropia de las ideas ajenas y las expone con su propia redacción o usando un modo de exposición propio ${ }^{15}$. Este punto debe ser destacado cuando se instruye a los estudiantes sobre las exigencias de la ética de la investigación. Es frecuente que, ante la imputación de plagio, el alumno se defienda alegando que no copió textualmente, sino que resumió o parafraseó las ideas ajenas con sus propias palabras. Se debe insistir, pues, en que el hecho de resumir o parafrasear no exime de la obligación de citar la fuente de las ideas ${ }^{16}$.

15 Para referirse al primer tipo de plagio descrito arriba se suele hablar de "plagio servil". Para referirse a la segunda clase se habla de "plagio inteligente". Véase, por ejemplo, Rojas, Miguel \& Olarte, Jorge (2010): "Plagio en el ámbito académico", Revista Colombiana de Anestesiología, 38, p. 537.

16 La guía sobre buenas prácticas académicas de la Universidad de Oxford considera que, quien parafrasea un texto ajeno y cambia unas pocas palabras y su orden, comete plagio incluso en el caso de que incorpore una referencia al autor original. Según la
En quinto lugar, para que se cometa plagio no es necesario que el autor de la obra plagiada esté completamente excluido de las notas o de la bibliografía. Si se reproduce, por ejemplo, un párrafo de una obra ajena sin la correspondiente referencia a su autor, se comete plagio aun cuando en la bibliografía aparezca citada la obra de la cual se extrajo el párrafo en cuestión.

Finalmente, para que se cometa plagio no es necesario que el plagiario actúe sin el consentimiento del plagiado. Cabe también el plagio "consentido", que sigue siendo inmoral porque constituye un engaño contra terceros y atenta contra el interés público en conocer al verdadero autor de una obra ${ }^{17}$.

\section{ILICITUD MORAL DEL PLAGIO}

Quizá podría pensarse que no faltan razones para reivindicar el plagio y defenderlo ante sus impugnadores. Cabría argumentar, por ejemplo, que, si el conocimiento y la ciencia son un patrimonio común de

guía de Oxford, quien así procede crea una impresión engañosa de que los textos parafraseados son propios. Lo que la guía sugiere es usar palabras propias para "escribir un resumen breve del argumento completo del autor" (University of Oxford, s. f., p. 7). En mi opinión, calificar como plagio a la paráfrasis que incluye referencia es un error. De hecho, el recurso a la paráfrasis puede ser hasta conveniente, pues permite evitar las citas textuales excesivas. Por otro lado, conservar algunas palabras o expresiones del autor es una vía legítima para mantener la fidelidad al texto original. $\mathrm{Si}$, en cambio, otras palabras son prescindibles, una llaneza de estilo puede aconsejar eliminarlas. Del mismo modo, la sistematización de quien comenta el texto ajeno puede sugerir un cambio de orden de las expresiones originales, que es razonable si no altera el sentido del texto utilizado. En síntesis, mientras se incorpore la adecuada referencia al autor, la paráfrasis de una idea ajena me parece un recurso legítimo en la escritura científica.

17 Véase Toller (2011) pp. 88-89. 
todos los hombres, nadie puede oponerse a que ese conocimiento y esa ciencia se difundan tan libre y gratuitamente como sea posible. La limitación del libre uso de una información que por su naturaleza es un bien común de la humanidad sería, así, una muestra de egoísmo. Además, se podría agregar que la propiedad privada $-\mathrm{y}$ la facultad de exclusión que la constituye- solo se funda en el carácter limitado de la utilidad que prestan los bienes materiales, que por su naturaleza no pueden servir a todos. Pero los bienes intelectuales -como una teoría filosófica o científica, o unos versos hermosos- son de suyo inagotables o comunicables ilimitadamente, por lo que no es razonable afirmar que sobre ellos existe un derecho de propiedad privada.

Si se argumentara del modo antedicho se incurriría, sin embargo, en errores importantes. En primer lugar, la proscripción del plagio no se opone al avance y a la difusión de la ciencia y del conocimiento. Uno es libre, de hecho, de invocar cualquier teoría de otro. La única exigencia es que incorpore una cita o referencia en la que conste la autoría ajena. En segundo lugar, respecto de las producciones científicas (como también de las artísticas) sí se cumplen las condiciones para que pueda existir una propiedad privada. El iusfilósofo chileno Rafael Fernández Concha expuso, con claridad meridiana, el argumento que avala esta posición. Aquí, por consiguiente, me limito a reproducir sus palabras:

“... reservándose la reproducción de sus obras, el escritor, el escultor, el pintor, etc., no impiden a nadie trabajar sobre los mismos asuntos. [...] los autores de obras originales en ciencias o artes no se reservan ni nociones, ni procedimientos, ni argu- mentos, ni métodos, ni aun prohíben el examen de sus producciones para beber en ellas ideas e inspiraciones, y sacar de las mismas todo el provecho posible en orden a la composición de otras distintas o semejantes. Dichas propiedades $[i$. e., la literaria y la artística] importan solo la reserva de un tipo que lleva el sello imborrable de la personalidad de su autor, que es obra exclusiva de su ingenio, que no puede ser producido por otro alguno" 18 .

\section{Y luego concluye:}

"No se contiene, por lo tanto, en las propiedades de que hablamos, la apropiación de cosa que pertenezca al campo de la actividad de todos o al dominio común de los hombres, o que sea de utilidad ilimitada; y no hay, por lo mismo, nada que obste a la aplicación del principio que atribuye exclusivamente a cada cual el fruto de su habilidad y trabajo" ${ }^{19}$.

A la luz de lo anterior, puede verse que el plagio es ilícito, primero, porque viola el derecho de propiedad del autor de la obra plagiada. Nuestra ley de propiedad intelectual (ley 17.336, de 1970) señala, en el inciso $2 .^{\circ}$ de su artículo $1 .^{\circ}$, que "[e]l derecho de autor comprende los derechos patrimonial y moral, que protegen el aprovechamiento, la paternidad y la integridad de la obra”. Pues bien, el plagio, junto con lesionar directamente el derecho al

\footnotetext{
18 Fernández Concha, Rafael (1966): Filosofía del Derecho o Derecho Natural, tomo II (3. ${ }^{\text {a }}$ ed., Santiago, Editorial Jurídica de Chile) pp. 69-70.

19 Fernández Concha (1966) p. 70.
} 
reconocimiento de la paternidad de la obra, puede igualmente lesionar el derecho patrimonial del autor, si lo priva de la justa compensación por el fruto de su trabajo, y puede lesionar incluso su derecho a preservar la integridad de la obra, como sucede cuando el plagio va unido a una deformación de la obra plagiada ${ }^{20}$. Sobre esto último podemos recordar de nuevo las quejas de Marcial contra el plagiario Fidentino:

"Lo que recitas, Fidentino, es mi libro, pero cuando recitas mal, empieza a ser tuyo" 21 .

Además de las ya dichas, hay otras razones que permiten concluir la inmoralidad del plagio de modo cierto. Enumero, a continuación, tres, sin pretensiones de ser exhaustivo.

En primer lugar, el plagio es ilícito porque es una forma de simulación, la que, a su vez, es una forma de mentira. El plagiario miente, pues presenta una obra ajena como si fuera propia. Por este motivo, obran contra el plagio todas las razones que permiten oponerse a la mentira. Así: (a) el plagio atenta contra el bien del conocimiento de la verdad, pues deforma la realidad e induce el error en el otro; (b) el plagio también atenta contra el bien de la adecuada vida social, en la medida en que la mentira socava la confianza que es necesaria para la convivencia pacífica entre los hombres; y (c), el plagio atenta contra el bien de la autenticidad o integridad de la persona, en cuanto quiebra la armonía que debe existir entre sus aspectos internos y externos, es decir, entre lo que sabe (sus pensamientos y

\footnotetext{
20 Véanse Rojas y Olarte (2010) p. 538; Tollek (2011) p. 87.

21 Marcial (2001) Epigramas, I, p. 38.
}

sus creencias) y el modo como se manifiesta al exterior.

En segundo lugar, el plagio es ilícito porque erosiona los fundamentos de la cultura universitaria. Esta incentiva el esfuerzo personal y la reflexión original. Aquel, por el contrario, fomenta la pereza y desincentiva el trabajo dedicado y riguroso. Si la universidad es una comunidad de personas que aúnan sus esfuerzos en la búsqueda de la verdad, entonces es manifiesto que el plagio, al ser una forma de mentira, contradice el êthos mismo de la vida universitaria.

En tercer lugar, el plagio viola el legítimo interés social en conocer al autor de la obra $^{22}$. Hay, en efecto, muchas razones de bien común para que la comunidad quiera conocer con verdad al autor. Un autor conserva, en general, su derecho a permanecer anónimo o a usar un seudónimo, pero eso es distinto al engaño que se produce con el plagio.

\section{PRINCIPIO DE PRESUNCIÓN DE AUTORÍA Y DERECHO DE CITA}

En un trabajo académico se presume siempre que lo que el autor presenta es un desarrollo propio y original. Esta presunción solo se desvirtúa mediante la cita o la referencia de la fuente de la que se extrajeron las ideas o datos. Por lo mismo, si falta la cita respectiva, se presume que el autor presenta su exposición como si fuera propia y original. De ahí, pues, que, en ausencia de la cita de las fuentes, nadie pueda excusarse de la imputación de plagio mediante el alegato de que no señaló expresamente que las ideas contenidas en el trabajo fueran propias.

22 Véase Toller (2011) p. 87. 
La cita, entonces, es la vía que tiene el investigador para dar a conocer a sus potenciales lectores que una determinada información contenida en el trabajo procede de otra fuente. Puesto que el uso de la correspondiente cita es importante para deslindar lo propio de lo ajeno, es necesario que el investigador domine adecuadamente los sistemas de citación y de elaboración de notas $^{23}$.

Pero es importante destacar que el investigador no solo tiene el deber de citar: también tiene un derecho a citar. El denominado "derecho de cita" permite armonizar el respeto por la autoría ajena de las ideas con la necesaria difusión del conocimiento, que también es una exigencia del bien común. El profesor argentino Fernando Toller expresa esto con claridad:

"El reconocimiento del derecho de cita tiene por objeto alcanzar un equilibrio entre los derechos de exclusividad de los autores, por una parte -que no puede exigir el hermetismo ajeno sobre su obra-, y el progreso literario, artístico, técnico y científico a través de la utilización libre y gratuita de las obras protegidas, por la otra, siempre bajo el cumplimiento de ciertos parámetros" 24 .

El derecho de cita se encuentra reconocido incluso en documentos jurídicos. Así, en el ámbito internacional, el Convenio de Berna para la Protección de las Obras Literarias y Artísticas $^{25}$ establece, en su artículo 10 n. ${ }^{\circ}$ 1, que "son lícitas las citas tomadas

\footnotetext{
23 Véase Toller (2011) p. 86.

24 Toller (2011) p. 91.

25 Este Convenio fue suscrito el 9 de septiembre de 1886, y ha sido completado y revisado en numerosas oportunidades.
}

de una obra que se haya hecho lícitamente accesible al público, a condición de que se hagan conforme a los usos honrados y en la medida justificada por el fin que se persiga”. El mismo artículo agrega, en su numeral tercero, que "las citas y utilizaciones a que se refieren los párrafos precedentes deberán mencionar la fuente y el nombre del autor, si este nombre figura en la fuente". Por su parte, en la legislación nacional se reconoce el derecho de cita en el artículo $71 \mathrm{~B}$ de la ley de propiedad intelectual, que dispone: "Es lícita la inclusión en una obra, sin remunerar ni obtener autorización del titular, de fragmentos breves de obra protegida, que haya sido lícitamente divulgada, y su inclusión se realice a título de cita o con fines de crítica, ilustración, enseñanza e investigación, siempre que se mencione su fuente, título y autor”. A su vez, el reglamento de la ley señala, en su artículo 6. ${ }^{\circ}$, que "se entiende por fragmento [...] la reproducción de un párrafo de una obra literaria manuscrita o dactilográfica que no exceda de 10 (diez) líneas"26.

Como sucede con otros derechos, también se puede abusar del derecho de cita. El recurso desmedido al derecho de cita no constituye plagio, pero es una práctica académica que debe evitarse. Es poco científico el trabajo que está, en su mayor

\footnotetext{
26 Esta determinación dista, sin embargo, de ser precisa. En efecto, más exacto hubiese sido fijar una cierta cantidad de caracteres, pues las líneas pueden variar según el tamaño de la letra, la extensión de los márgenes, etc. El artículo 10 de la Ley 11.723, que establece el régimen legal de la propiedad intelectual en Argentina, es más preciso, en este sentido, que la ley chilena, pues señala: "Cualquiera puede publicar con fines didácticos o científicos, comentarios, críticas o notas referentes a las obras intelectuales, incluyendo hasta mil palabras de obras literarias o científicas $\mathrm{u}$ ocho compases en las musicales y en todos los casos solo las partes del texto indispensables a ese efecto".
} 
parte, construido con extractos de otras obras, aunque en cada caso se cite la obra utilizada como fuente ${ }^{27}$.

\section{ALGUNAS FORMAS ESPECIALES DE PLAGIO}

Una forma particular de plagio, cuya práctica se viene extendiendo especialmente entre los estudiantes universitarios de pregrado, es la de pagar por la confección de las tesis o memorias de grado. Esto es una forma de plagio, pues, como ya se ha indicado, para que se cometa plagio no es necesario que la conducta sea contraria al consentimiento del autor plagiado. Por otro lado, la elaboración de una memoria o tesis es un requisito con el que debe cumplir el alumno para acreditar que posee determinadas competencias que lo capacitan para obtener el título de que se trate. Así pues, pagar a un tercero por la confección de una tesis es tanto como pagarle a alguien para que nos suplante al rendir un examen. Resulta sorprendente, por lo mismo, que hoy en día existan en nuestro país sitios web, como www.sehacentesis.cl, donde se ofrecen servicios de "realización completa de la tesis a solicitar", y con desfachatez se describen estos servicios como "asesorías extraeducacionales".

Este es el lugar adecuado para decir que se debe proscribir también, enérgicamente, la práctica de dirigir tesis o memorias que consistan en una transcripción de las clases del mismo director. Aunque no me parece que se pueda decir que comete plagio el director que luego publica la tesis como propia (puesto que se trata de una transcripción de lo que él ha dicho), la práctica desvirtúa el sentido

Véase Toller (2011) p. 91. de una memoria o tesis, que es hacer un aporte al avance de la ciencia -aunque solo sea sistematizando el estado de la cuestión-, y no desarrollar las habilidades mecanográficas del alumno. En cualquier caso, si la acción ya se ha realizado y el alumno ha puesto trabajo importante de su parte -por ejemplo, una redacción más ordenada y cuidada, o la búsqueda de todas las referencias que el profesor hace verbalmente en la clase-, lo justo sería agregarlo como coautor del trabajo, y detallar, en el prólogo, en la introducción o en otro apartado inicial, la participación que ha tenido cada uno de los autores en la elaboración de la obra.

Una forma paradójica de plagio, porque parece constituir una contradicción en los términos, es el denominado autoplagio. En los últimos años, en el medio anglosajón, se ha condenado fuertemente este self-plagiarism, y esa tendencia también ha llegado a nuestro medio. En julio de 2011, Bernardo González Ojeda, ex Presidente del Consejo Superior de Ciencia de Fondecyt, publicó, en el portal institucional, una columna titulada Malas conductas cientificas, en la que abordaba, entre otros, los problemas del plagio y del autoplagio. González señala que, en los últimos años, los Consejos Superiores de Fondecyt han detectado un número creciente de situaciones de mala conducta científica. La forma más común de esta mala conducta en los proyectos de investigación es el plagio. Pero también se han detectado -añade González- casos de autoplagio, esto es, de "uso de información ya publicada, sin indicarlo, generada por el investigador responsable, como parte de lo que se propone realizar en [el] proyecto en concurso" 28 . Como los casos han ido

28 GonzÁlez, Bernardo (2011): "Malas conductas científicas". Disponible en: http://www.fondecyt. 
en aumento, Fondecyt ha decidido castigar estas prácticas con severidad. Así, señala González que cuando se detectan situaciones de mala conducta científica el proyecto queda fuera de bases y, en los casos más graves, el investigador responsable puede ser sancionado con inhabilitación para postular a concursos Fondecyt hasta por cinco años.

La práctica del autoplagio también ha sido tipificada para el caso de los estudiantes. Así, la guía sobre buenas prácticas académicas de la Universidad de Oxford califica como autoplagio la acción de presentar, para evaluación, un trabajo que ya ha sido presentado para cumplir con los requisitos de otro curso ${ }^{29}$.

En este escenario, vale la pena reflexionar un poco más sobre qué prácticas han sido consideradas como autoplagio y cuáles son las razones que podrían existir para condenarlas. Algunos autores han llegado a comparar el autoplagio con la acción del que simula un robo a sí mismo para cobrar un seguro. No es superfluo, por tanto, analizar si ese fuerte juicio de reproche se apoya sobre bases sólidas.

Se suelen considerar bajo el rótulo de autoplagio, principalmente, las tres prácticas siguientes: (i) publicar el mismo trabajo en lugares distintos con títulos diferentes; (ii) usar, en una nueva obra, material ya publicado; y (iii), para el caso particular de los estudiantes, presentar, para que sea evaluado en un curso, un trabajo que se ha presentado previamente para cumplir con los requisitos de otro curso.

En mi opinión, lo primero que hay que tener en cuenta es que estas acciones no son malas en sí mismas, y por eso las

cl/578/article-38580.html [fecha de consulta: 7 de septiembre de 2012].

29 Véase University of OXford (s. f.) p. 8. circunstancias o las intenciones del sujeto agente pueden mutar el juicio moral.

Por regla general, entonces, convengo en que no es correcto publicar el mismo trabajo en lugares distintos con títulos diferentes. Normalmente, esto se hace para engrosar artificialmente la lista de publicaciones, y en esa medida es engañoso o, en el mejor de los casos, conducente a error. La regla fundamental en esta materia es que el "principio de individuación" de los trabajos académicos es la particular contribución al conocimiento de la verdad que en ellos se realiza o lleva a cabo. Eso es lo que individúa a cada trabajo y lo distingue de otro, y no el lugar donde se haya publicado. Por eso, quien enumera como tres publicaciones distintas el mismo trabajo publicado en tres lugares diferentes engaña a los evaluadores del curriculum y, por lo mismo, produce competencia desleal, al originar una ventaja académica injusta. La publicación en duplicado (o en triplicado) también engaña a los compradores -quienes razonablemente esperan algo nuevo- $y$, eventualmente, también engaña a la editorial, si no se le ha expresado esa circunstancia. La editorial, en efecto, se expone a perder prestigio y recursos ${ }^{30}$.

Pero la doble publicación, como he dicho, no es en sí misma mala, por lo que puede ser razonable en determinadas circunstancias. Por ejemplo, puede dar a conocer una importante información a un conjunto de personas que, por diversas razones, no pudieron tener acceso (o acceso fácil) a la primera publicación. Desde luego, cuando la nueva publicación se hace en otra lengua, se beneficia a una audiencia nueva. Ocurre lo mismo cuando las publicaciones se realizan en territorios diferentes y con poca comu-

\footnotetext{
30 Véase Grisez, Germain (1997): Difficult Moral Questions (Illinois, Franciscan Press) p. 687.
} 
nicación, o en épocas diferentes (es indudablemente lícito republicar trabajos antiguos y difíciles de encontrar, aunque se lo haga bajo un nuevo título, más adecuado el nuevo lector). En algunos casos, el autor hace una primera publicación (por ejemplo, en las actas de un congreso) que le permite recibir críticas e incorporarlas a una nueva edición, que estará destinada a una revista especializada. Nada de esto parece reprochable ${ }^{31}$.

Si el mismo trabajo se publica en lugares distintos con títulos diferentes en un espacio de tiempo muy breve y en ambientes con fácil comunicación, la acción puede ser más difícil de justificar, pero aun así no será imposible de justificar. Se justificaría, por ejemplo, si la primera edición se vendió muy rápido y el autor puede acceder a una mejor editorial para la segunda edición, pero esta nueva editorial exige cambiar el título de la obra por uno más atractivo. En un caso así, la doble publicación sería lícita, con tal de que se advierta del modo más claro posible que el libro fue publicado antes con un título diverso.

La segunda acción considerada como autoplagio, esto es, usar, en una nueva obra, material ya publicado, me parece aun más fácil de justificar desde el punto de vista moral. Si una idea ha quedado muy bien expresada en un párrafo de un trabajo anterior, y es pertinente reproducir esa idea en un trabajo nuevo, no veo por qué no pueda ser lícito que su autor la use nuevamente. $\mathrm{O}$ sea, si un autor piensa que un párrafo anterior le ha quedado muy bien logrado, me parece escrupuloso pedirle que se esfuerce por escribirlo de modo diferente, aunque sea peor, solo para no repetir sus palabras. Por la misma razón, pienso que es lícito también usar las mismas citas en varios lu-

31 Véase Grisez (1997) p. 687. gares diferentes. En definitiva, el solo hecho de reproducir una frase o un párrafo ya publicado por el mismo autor, no constituye una falta ni contra la justicia ni contra la veracidad. Por cierto, si el texto reproducido fuese de una extensión considerable, correspondería dejar constancia de la situación; por ejemplo, declarando que uno se está valiendo de las ideas ya expuestas en un determinado trabajo anterior.

La tercera práctica caracterizada como autoplagio tampoco es de suyo, en mi opinión, un atentado contra la justicia o contra la veracidad. Esto se debe a que, en principio, no hay razones para prohibir que alguien se valga del fruto de sus esfuerzos anteriores. De hecho, en algunos casos sucede que es el mismo profesor a cargo del curso quien sugiere a los alumnos que mejoren o amplíen un trabajo ya realizado, sin importar si lo han realizado en la misma asignatura o en otra. Con todo, tampoco parece razonable que, a lo largo de toda su carrera, un alumno presente el mismo trabajo cada vez que la amplitud del tema exigido en una asignatura se lo permita. Además, los profesores piden trabajos con la intención de que los alumnos se ejerciten en las técnicas de investigación y redacción científicas, y esta finalidad no se cumple si el alumno presenta siempre el mismo trabajo. Me inclino a pensar, por tanto, que lo más aconsejable sería dar instrucciones explícitas sobre el grado de originalidad que se exigirá en cada caso, siempre con miras a evitar posibles abusos. Hay que tener en cuenta, por último, que ciertos trabajos han de ser, por su naturaleza, investigaciones de carácter original, que hagan una nueva contribución al conocimiento de la verdad. Por tal razón, no es aceptable, por ejemplo, que una misma persona obtenga dos doctorados distintos presentando la misma tesis. 


\section{MEDIDAS CONTRA EL PLAGIO}

La lucha contra el plagio ha de comenzar, desde luego, poniendo los medios para que, quienes desarrollan alguna actividad de investigación científica (en particular los que se inician en ella), adquieran la conciencia de que también en este ámbito hay reglas morales específicas que deben seguirse. Es decir, es necesario enseñar que el plagio es ilícito y por qué lo es. Esto puede parecer obvio, pero a lo que me refiero es que hoy no podemos simplemente dar por supuesto que se trata de materias sabidas. Los que imparten cátedras de metodología de la investigación, o análogas, debieran, por tanto, incorporar, en algún nivel, este tipo de reflexiones morales, que, por lo demás, permitirán dar pleno fundamento y sentido a las enseñanzas técnicas sobre citas, referencias y elaboración de repertorios bibliográficos. El alumno podrá darse cuenta de que todas esas instrucciones técnicas no tienen por objeto hacerle la vida más difícil, sino enseñarle a distinguir con claridad, por medio de criterios estandarizados, lo propio de lo ajeno en el terreno de las ideas.

A la hora de instruir al alumno en estas materias, se debe procurar que logre la mayor claridad posible sobre el alcance o extensión de lo que se califica como plagio. Por ejemplo, el alumno deberá saber que no se excusa del plagio el que alega que solo está copiando sus notas o sus resúmenes de libros, pues el hecho de hacer el resumen de un libro no transforma en propias las ideas resumidas. También se debe insistir, por ejemplo, en que no es excusa para dejar de respetar la autoría ajena de las ideas el hecho de que no se pueda dar con la fuente de la información. El investigador siempre tiene que esforzarse por conseguir la cita directa, pero, en caso de que esto no le sea posible en las circunstancias en que se encuentra, la cita oblicua o indirecta pasa a ser obligatoria. El profesor que encomienda un trabajo a sus alumnos debe precisar el grado de originalidad que se exige, y también el nivel de colaboración permitido. La colaboración no autorizada entre estudiantes que realizan un trabajo también es una forma de plagio, denominada "colusión" 32

En su The Little Book of Plagiarism, Richard Posner sostiene que en los tiempos actuales es ingenuo pretender erradicar el plagio por la sola vía de predicar a los estudiantes la malicia moral que él conlle$\mathrm{va}^{33}$. En este punto convengo con el jurista norteamericano. Como dije al comienzo, algunos llegan a la universidad con la práctica del copy-paste convertida en hábito, y respecto de ellos las admoniciones pueden surtir poco o ningún efecto. Posner promueve el recurso a los softwares de detección de plagio, lo que me parece una buena idea. De hecho, si la computación ha dado ocasión para que el problema del plagio aumente de modo exponencial, es razonable que busquemos en ella también alguno de los remedios para combatirlo.

En cualquier caso, la sugerencia de Posner versa propiamente sobre una medida para detectar el plagio. Y, en lo que a esto se refiere, es posible utilizar cualquier medio lícito. A veces será fácil detectar el plagio, como cuando un profesor recibe dos trabajos con partes idénticas. En otros casos, aunque no le conste fehacientemente, el profesor puede tener sospechas fundadas de que ha habido plagio, como cuando en un breve tiempo aumenta sustancialmente la calidad de la expresión escrita de un alum-

\footnotetext{
32 Véase University of Oxford (s. f.) p. 7.

33 Véase Posner, Richard (2007): The Little Book of Plagiarism (New York, Random House) 128 pp.
} 
no, o cuando un estudiante que no se ha caracterizado por la elevada calidad de sus investigaciones presenta un trabajo pulcro y riguroso. En situaciones como estas, puede ser útil recurrir a un programa computacional para disipar la duda.

Dentro de las medidas para combatir el plagio es fundamental que, cuando este se detecte, el plagiario reciba la correspondiente sanción. En algunos casos el plagio puede conllevar responsabilidad por violación de las leyes que protegen la propiedad intelectual o los derechos de autor. Pero, con independencia de esto, si se da en el ámbito académico - por ejemplo, en la universidad-, el plagio debe siempre llevar aparejada una sanción disciplinar. En este sentido, es conveniente que la autoridad central fije las sanciones que se van a aplicar, y que ellas consten en los reglamentos que se dan a conocer al alumno al momento de incorporarse a la institución. De este modo se evita que se produzcan diferencias injustas entre los criterios que aplica cada profesor, o que algunos casos de plagio queden definitivamente sin sanción.

Como siempre, la magnitud de la sanción deberá ser determinada prudencialmente por la autoridad. O sea, no cabe señalar de modo universal cómo deben ser castigadas las distintas situaciones de plagio. Sin perjuicio de esto, en la aplicación de sanciones disciplinarias se deben tener en cuenta algunos criterios generales de justicia. Así, a modo de ejemplo, (i) la sanción ha de ser más grave en el caso de plagio intencional que en el caso de plagio por negligencia; (ii) la sanción debe aumentar en casos de reincidencia; (iii) hay que distinguir, naturalmente, entre los casos de plagio leve y los de plagio severo, como cuando se presenta una obra entera como propia, sin serlo; (iv) hay que distinguir, también, en- tre el plagio cometido por un alumno que recién se inicia en la vida universitaria y el cometido por un estudiante que ya conoce las exigencias de la educación superior; (v) la sanción debe ser más seria, ceteris paribus, respecto de aquellos que han decidido dedicarse profesionalmente a la investigación científica (como un alumno de doctorado o un académico), y (vi) en el caso de plagio severo en un trabajo de tesis para obtener el grado, la detección de plagio debería implicar la revocación del título, puesto que el candidato no ha cumplido verdaderamente con los requisitos para obtenerlo.

\section{ALGUNOS CONSEJOS PARA UNA "BUENA CONDUCTA CIENTÍFICA"}

Aunque el esfuerzo de la ética de la investigación científica se ha centrado principalmente en definir de modo preciso la "mala conducta en la investigación científica”, vale la pena situarse en la perspectiva inversa y enumerar algunas buenas prácticas. Así como existe la noción del buen padre de familia, uno podría hablar aquí del buen investigador (sea académico o alumno). Para terminar, entonces, enunciaré, como corolario de lo expuesto, algunas características de un buen investigador. Un buen investigador se caracteriza por cumplir, entre otros, los siguientes deberes.

1. Un buen investigador identifica claramente lo que recoge de otros autores, y da crédito incluso a las buenas ideas que ha recibido verbalmente de otros.

2. Un buen investigador domina adecuadamente los sistemas de citación y de elaboración de notas.

3. Un buen investigador está al día en su propia disciplina: conoce a los 
principales autores y conoce la discusión relevante. De esta manera evita presentar erróneamente, como novedosas y originales, teorías que ya han sido formuladas por otros, $y$, de paso, disipa toda sospecha de plagio.

4. Un buen investigador conoce la ley sobre propiedad intelectual que rige en su país. Puesto que esta ley es relevante para su trabajo y se presume justa si procede de autoridad legítima (que es lo normal), el investigador debe conocerla a lo menos en general $^{34}$. Con todo, puesto que las prohibiciones que se establecen en este tipo de leyes no son siempre absolutas desde el punto de vista moral, ciertas circunstancias pueden eximir de su cumplimiento.

5. Un buen investigador, cuando envía a publicación una obra substancialmente idéntica a otra que ha publicado previamente, siempre expresa esta circunstancia. Desde luego al editor, pero también a los potenciales lectores. Y siempre en un lugar de fácil acceso.

6. En su lista de publicaciones (por ejemplo, en un curriculum vitae), un buen investigador identifica claramente las reimpresiones o nuevas versiones de una publicación previa. Si la nueva es substancialmente igual a la anterior, el buen investigador la agrega dentro del mismo número, para evitar que una publicación en duplicado cuente como si fueran dos trabajos diversos. Finalmente:

7. Un buen académico investigador no deja sin sanción el plagio que descubre en sus alumnos. La condes-

34 Véase Grisez (1997) pp. 687-688 cendencia con el plagio solo cauteriza la conciencia del plagiario y torna más difícil el combate contra esta práctica que, como se indicó anteriormente, pone en serio riesgo el prestigio de la labor científica y de la institución universitaria como el lugar propio de ella.

\section{BIBLIOGRAFÍA CITADA}

Aluja, Martín, \& Birke, Andrea (2004): "Panorama general sobre los principios éticos aplicables a la investigación científica y la educación superior”, en: Aluja, M. \& Birke, A. (coords.). El papel de la ética en la investigación científica y la educación superior (México, Fondo de Cultura Económica, Segunda Edición) pp. 87-143.

Casares, Julio (2004): Diccionario ideológico de la lengua española (Barcelona, Gustavo Gili, Segunda Edición) 887 pp.

Corominas, Joan (1973): Breve diccionario etimológico de la lengua castellana (Madrid, Gredos, Tercera Edición). Corominas, Joan, \& Pascual, José (19911997): Diccionario crítico etimológico castellano e hispánico (Madrid, Gredos).

Domínguez, César, \& Macías-Ordóñez, Rogelio (2004): “'El que no transa no avanza': la ciencia mexicana en el espejo", en Aluja \& Birke (coords.), El papel de la ética en la investigación científica y la educación superior (México, Fondo de Cultura Económica, Segunda Edición) pp. 219-243.

Fernández Concha, Rafael (1966): Filosofía del Derecho o Derecho Natural, tomo II (Santiago, Editorial Jurídica de Chile, Tercera Edición) 565 pp.

GonzÁlez, Bernardo (2011): "Malas conductas científicas". Disponible en: http://www.fondecyt.cl/578/arti- 
cle-38580.html [fecha de consulta: 7 de septiembre de 2012].

Grisez, Germain (1997): Difficult Moral Questions (Illinois, Franciscan Press) 927 pp.

Marcial, Marco Valerio, Epigramas (trad. A. Ramírez, Gredos, Madrid, 2001).

Mommsen, Teodoro (1999): Derecho Penal romano (trad. P. Dorado, Santa Fe de Bogotá, Temis).

Moliner, María (2007): Diccionario de uso del español (Madrid, Gredos, Tercera Edición).

Oxford Latin Dictionary (1968), (Oxford: Clarendon Press) 2126 pp.

University Of Oxford (s. f.): "Academic Good Practice. A Practical Guide". Disponible en: http://www.ox.ac.uk/media/ global/wwwadminoxacuk/localsites/ educationcommittee/documents/Academic_good_practice_a_practical_guide. pdf [fecha de consulta: 7 de septiembre de 2012].

Office of Research Integrity of the

U.S. Department of Health and Human Services (s. f.): "Definition of Research Misconduct”. Disponible en: http://ori.hhs.gov/misconduct/definition_misconduct.shtml [fecha de consulta: 7 de septiembre de 2012].
Posner, Richard (2007): The Little Book of Plagiarism (New York, Random House) $128 \mathrm{pp}$.

Real Academia Española (2001): Diccionario de la lengua española (Madrid, Espasa, Vigésima segunda Edición).

Rojas, Miguel, \& Olarte, Jorge (2010): "Plagio en el ámbito académico", Revista Colombiana de Anestesiología, 38, pp. 537-538.

Seco, Manuel; Andrés, Olimpia; \& RAmos, Gabino (1999): Diccionario del español actual (Madrid, Aguilar).

Toller, Fernando (2011): "Propiedad intelectual y plagio en trabajos académicos y profesionales", Revista la Propiedad Inmaterial, 15, pp. 85-97.

\section{NORMAS CITADAS}

Ley No 17.336, Propiedad Intelectual. Diario Oficial, 2 de octubre de 1970.

Decreto No 1122, Reglamento para la aplicación de la Ley No 17.336, de 2 de octubre de 1970, sobre Propiedad Intelectual. Diario Oficial, 17 de junio de 1971.

Convenio de Berna para la Protección de las Obras Literarias y Artísticas, 9 de septiembre de 1886. 